affected births, in spite of the increase in the numbers diagnosed prenatally.

We thank Christina Kelekun and Karen Wells for data entry and verification. The heads of the cytogenetic laboratories of England and Wales and the Association of Clinical Cytogeneticists provide continued support and data.

Contributors: EA was the grant holder and director of research and contributed in discussion and to the drafting of the manuscript; she is guarantor for the study. RGI was responsible for the development and efficiency of the coding and data entry for the register from 1989 to 1997. DM was project coordinator and cytogeneticist for the register with responsibility for analysing the data and writing the manuscript.

Funding: The register was initially funded by the Medical
Research Council; since 1994 it has been funded by North and South Thames NHS Research and Development.

Conflict of interest: None.

1 Morris JK, Mutton DE, Ide R, Alberman E, Bobrow M. Monitoring trends in prenatal diagnosis of Down's syndrome in England and Wales, 1989-1992. J Med Screen 1994;1:233-7.

2 Office for National Statistics. Population trends. London: HMSO, 1998.

3 Huang T, Watt HC, Wald NJ, Morris JK, Mutton D, Alberman E. Reliability of statistics in Down's syndrome notifications. J Med Screen 1997;4:95-7.

4 Alberman E, Mutton D, Ide R, Nicholson A, Bobrow M. Down's syndrome births and pregnancy terminations in 1989 to 1993: preliminary findings. Br J Obstet Gynaecol 1995;102:445-7.

5 Haddow JE. Antenatal screening for Down's syndrome: where are we and where next? Lancet 1998;352:336-7.

(Accepted 16 April 1998)

\title{
Effect of parity, gravidity, previous miscarriage, and age on risk of Down's syndrome: population based study
}

\author{
Annabelle Chan, Kieran A McCaul, Rosemary J Keane, Eric A Haan
}

The increased risk of Down's syndrome with maternal age underlies the recommendation for older pregnant women to be offered screening by amniocentesis or chorionic villus sampling. Recently Schimmel et al suggested that increased parity was an independent risk factor for Down's syndrome, but their study was not population based and did not include terminations of pregnancy. ${ }^{1}$

Using statewide statistics on births and terminations of pregnancy we investigated whether the risk of Down's syndrome is increased independently of maternal age by maternal parity, gravidity, or previous miscarriage.

\section{Subjects, methods, and results}

South Australia has around 20000 births annually. The state collects data on birth defects that include maternal characteristics in both its perinatal and abortion statistics. These statutory collections are complemented by notifications from health professionals to the South Australian Birth Defects Register of defects in children detected within the first 5 years of life and by cytogenetic and necropsy reports. Each case of Down's syndrome included in these collections has been cytogenetically confirmed.

The effects of parity, gravidity, number of previous miscarriages, and mother's age (by single year of age) on risk of having a fetus with Down's syndrome were modelled separately using Poisson regression; then the effects of parity, gravidity, and previous miscarriage were modelled separately after adjustment for the effect of mother's age. Overdispersion was detected in all the Poisson models constructed, and an overdispersion factor was estimated using the square root of Pearson's $\chi^{2}$ divided by the number of degrees of freedom. $^{2}$ The analysis was performed using PROC GENMOD in SAS. ${ }^{3}$ Analyses were undertaken for 1986-95 and 1986-90, which was similar to the period of study of Schimmel et al (1981-9) and preceded the gradually increasing use of maternal serum screening for Down's syndrome.
Analysis using births and terminations of pregnancy showed no significant increase in risk for increase in parity or gravidity (table). When only births were analysed for 1986-95, the increased risks with increase in parity $(\mathrm{P}<0.001)$ and gravidity $(\mathrm{P}<0.01)$ were not significant after adjustment for age $(\mathrm{P}=0.46$ and $\mathrm{P}=0.75$ respectively); similar results were obtained for 1986-90 for increase in parity. The risk was not increased with the number of previous miscarriages, but the increase in risk with age was constant $(\mathrm{P}<0.001)$.

\section{Comment}

Schimmel et al studied live births alone among women of high parity attending one hospital. Their analysis of maternal age by five year age groups might have contributed to spurious results through truncation.

The low risk found in women of low parity may have resulted from the inadvertent exclusion of women of low parity who had had Down's syndrome diagnosed in their fetus prenatally elsewhere and spontaneously miscarried or terminated the pregnancy. ${ }^{1}$ Another Australian population based study found that older pregnant women who had had three or more previous births were less likely than those of lower parity to undergo amniocentesis or chorionic villus sampling, although all were eligible for a medical service rebate. ${ }^{4}$ We found a similar differential use of prenatal diagnosis in univariate analysis among South Australian women who were pregnant in 1991-6 (odds ratio $0.55(95 \%$ confidence interval 0.51 to 0.61$))$ and also found a similar higher use of these tests among women who had had a previous termination of pregnancy. These and other differences identified may reflect different degrees of knowledge about the availability of tests, concern about the possibility of having a disabled child, or attitudes towards termination of pregnancy. ${ }^{4}$

With the operation of selection factors and increasing use of prenatal diagnosis, risk estimates of Down's
Epidemiology Branch, South Australian Health Commission, PO Box 6, Rundle Mall, Adelaide, South Australia 5000, Australia

Annabelle Chan, senior medical consultant, pregnancy outcome unit

Kieran A McCaul, head, health statistics unit

Rosemary J Keane, midwife, pregnancy outcome unit

South Australian

Birth Defects

Register,

Department of

Medical Genetics and Epidemiology, Women's and

Children's Hospital,

North Adelaide,

South Australia

5006

Eric A Haan,

director

Correspondence to: Dr Chan chan.annabelle@ health.sa.gar.au

BMJ 1998;317:923-4 
Relative risk (per unit increase in variable) of Down's syndrome for age, parity, gravidity, and previous miscarriage, 1986-95 and 1986-90, South Australia

\begin{tabular}{|c|c|c|c|c|c|c|c|c|}
\hline \multirow[b]{3}{*}{ Variable } & \multicolumn{4}{|c|}{ Births and terminations } & \multicolumn{4}{|c|}{ Births only } \\
\hline & \multicolumn{2}{|c|}{$\begin{array}{l}1986-95 \text { (284 cases of Down's } \\
\text { syndrome, } 197912 \text { births) }\end{array}$} & \multicolumn{2}{|c|}{$\begin{array}{l}1986-90 \text { (128 cases of Down's } \\
\text { syndrome, } 98561 \text { births) }\end{array}$} & \multicolumn{2}{|c|}{$\begin{array}{l}1986-95 \text { (171 cases of Down's } \\
\text { syndrome, } 197912 \text { births) }\end{array}$} & \multicolumn{2}{|c|}{$\begin{array}{l}1986-90 \text { (100 cases of Down's } \\
\text { syndrome, } 98561 \text { births) }\end{array}$} \\
\hline & Relative risk (95\% Cl) & $P$ value & Relative risk ( $95 \% \mathrm{CI}$ ) & $P$ value & Relative risk $(95 \% \mathrm{Cl})$ & $P$ value & Relative risk $(95 \% \mathrm{Cl})$ & $P$ value \\
\hline \multicolumn{9}{|l|}{ Univariate analysis } \\
\hline Age & 1.202 (1.142 to 1.266$)$ & 0.0001 & 1.170 (1.097 to 1.247$)$ & 0.0001 & 1.129 (1.103 to 1.155$)$ & 0.0001 & 1.131 (1.099 to 1.165$)$ & 0.0001 \\
\hline Parity & 1.256 (0.997 to 1.581$)$ & 0.0769 & 1.260 (0.946 to 1.677$)$ & 0.1461 & 1.235 (1.105 to 1.380$)$ & 0.0006 & 1.245 (1.078 to 1.438$)$ & 0.0059 \\
\hline Gravidity & 1.176 (0.988 to 1.398$)$ & 0.0931 & 1.168 (0.940 to 1.452$)$ & 0.1944 & 1.131 (1.036 to 1.235$)$ & 0.0099 & 1.107 (0.977 to 1.254$)$ & 0.1269 \\
\hline \multicolumn{9}{|l|}{ Multivariate analysis } \\
\hline \multicolumn{9}{|l|}{ Parity and age: } \\
\hline Parity & $0.964(0.777$ to 1.196$)$ & 0.7378 & 0.990 (0.751 to 1.306$)$ & 0.9442 & $1.038(0.942$ to 1.145$)$ & 0.4554 & 1.032 (0.912 to 1.168) & 0.6215 \\
\hline Age & $1.206(1.142$ to 1.273$)$ & 0.0001 & 1.171 (1.093 to 1.254$)$ & 0.0001 & 1.125 (1.098 to 1.153$)$ & 0.0001 & 1.128 (1.094 to 1.163$)$ & 0.0001 \\
\hline \multicolumn{9}{|l|}{ Gravidity and age: } \\
\hline Gravidity & 0.961 (0.810 to 1.141$)$ & 0.6463 & 0.972 (0.778 to 1.215$)$ & 0.8006 & 0.987 (0.909 to 1.071$)$ & 0.7541 & 0.949 (0.846 to 1.065$)$ & 0.3637 \\
\hline Age & 1.208 (1.143 to 1.276$)$ & 0.0001 & $1.173(1.095$ to 1.258$)$ & 0.0001 & 1.130 (1.102 to 1.159$)$ & 0.0001 & 1.138 (1.100 to 1.177$)$ & 0.0001 \\
\hline Previous miscarriage & $0.929(0.642$ to 1.344$)$ & 0.6865 & 0.875 (0.516 to 1.483$)$ & 0.6003 & $0.933(0.777$ to 1.121$)$ & 0.4480 & 0.743 (0.529 to 1.044$)$ & 0.0584 \\
\hline Age & 1.205 (1.142 to 1.270$)$ & 0.0001 & 1.173 (1.098 to 1.254$)$ & 0.0001 & 1.131 (1.103 to 1.159$)$ & 0.0001 & 1.138 (1.098 to 1.179$)$ & 0.0001 \\
\hline
\end{tabular}

syndrome need to be based on population data that include births and terminations of pregnancy.

We acknowledge the role of South Australian midwives and neonatal nurses in providing perinatal data and of doctors in providing data on congenital abnormalities; the contribution of staff of the South Australian Births Defects Register and the Pregnancy Outcome Unit in processing and collating data on babies with Down's syndrome, births, and terminations of pregnancy; and the staff of the department of cytogenetics and molecular genetics, Women's and Children's Hospital, and of the department of cytogenetics, Queen Elizabeth Hospital, for providing cytogenetic data.

Contributors: AC initiated and planned the study, reviewed the literature, performed the univariate analysis, participated in the interpretation of data, and wrote the paper. KAM performed the Poisson regression analysis and participated in the planning of the study, the interpretation of data, and writing the paper. RJK participated in the planning of the study, the validation of some case details, the retrieval and preparation of data for analysis, and editing the manuscript. EAH participated in planning the study, interpreting the data, and editing the manuscript. $\mathrm{AC}$ and $\mathrm{KAM}$ are guarantors for the paper.

Funding: None.

Conflict of interest: None.

1 Schimmel MS, Eidelman AI, Zadka P, Kornbluth E, Hammerman C. Increased parity and risk of trisomy 21: review of 37110 live births [with commentary by R Lilford]. BMJ 1997;314:720-1.

2 McCullagh P, Nelder JA. Generalised linear models. 2nd ed. London: Chapman and Hall, 1989.

3 SAS Institute. SAS/STAT Software: The GENMOD procedure, release 6.09. Cary, NC: SAS Institute, 1993.

4 Halliday J, Lumley J, Watson L. Comparison of women who do and do not have amniocentesis or chorionic villus sampling. Lancet $1995 ; 345: 704-9$.

(Accepted 27 February 1998)
Highfield

Adolescent Unit,

Warneford Hospital,

Oxford OX3 7JX

G Salmon,

senior registrar in

child and adolescent

psychiatry

A James,

consultant in child

and adolescent

psychiatry

continued over

BMJ 1998;317:924-5
Evidence exists of considerable problems with bullying and bullied children in secondary schools. In the largest survey in the United Kingdom to date $10 \%$ of pupils reported that they had been bullied "sometimes or more often" during that term, with $4 \%$ reporting being bullied "at least once a week." The impact of the introduction of policies on bullying throughout a school seems to be limited. ${ }^{1}$ The commonest type of bullying is general name calling, followed by being hit, threatened, or having rumours spread about one. ${ }^{1}$ Bullying is thought to be more prevalent among boys and the youngest pupils in a school. ${ }^{2}$

We are unaware of any study that has examined the mental health problems of children who are being bullied. We assessed self reported anxiety, depression, and self esteem in bullied children and those who were not bullied and in bullies and those who were not bullies.

\section{Subjects, methods, and results}

Four questionnaires (the Olweus bully/victim, ${ }^{2}$ the short mood and feelings, ${ }^{3}$ the revised children's manifest anxiety incorporating a lie scale, ${ }^{4}$ and the Rosenberg self esteem ${ }^{5}$ questionnaires) were anonymously completed by 904 pupils aged 12-17 in years 8-11 in two coeducational secondary schools. School A is a non-selective school in a socially disadvantaged urban area. School B is a rural grant maintained school in an area with a higher than average proportion of high social class households.

Logistic regression models were fitted to the proportions of bullied or bullying children using STATA. Categorical variables were school, school year, and sex. Anxiety, lying, esteem, and depression scores were treated as continuous variables. The table shows the odds ratios of the fitted logistic regression models. 